\title{
Revised Max-Min Average Composition Method for Decision Making Using Intuitionistic Fuzzy Soft Matrix Theory
}

\author{
P. Shanmugasundaram, ${ }^{1}$ C. V. Seshaiah, ${ }^{2}$ and K. Rathi ${ }^{1}$ \\ ${ }^{1}$ Department of Mathematics, Velalar College of Engineering \& Technology, Tamil Nadu 638012, India \\ ${ }^{2}$ Department of Mathematics, Sri Ramakrishna Engineering College, Tamil Nadu 641022, India \\ Correspondence should be addressed to P. Shanmugasundaram; psserode@gmail.com
}

Received 15 July 2014; Revised 29 July 2014; Accepted 2 August 2014; Published 20 August 2014

Academic Editor: Salvatore Sessa

Copyright (c) 2014 P. Shanmugasundaram et al. This is an open access article distributed under the Creative Commons Attribution License, which permits unrestricted use, distribution, and reproduction in any medium, provided the original work is properly cited.

In this paper a revised Intuitionistic Fuzzy Max-Min Average Composition Method is proposed to construct the decision method for the selection of the professional students based on their skills by the recruiters using the operations of Intuitionistic Fuzzy Soft Matrices. In Shanmugasundaram et al. (2014), Intuitionistic Fuzzy Max-Min Average Composition Method was introduced and applied in Medical diagnosis problem. Sanchez's approach (Sanchez (1979)) for decision making is studied and the concept is modified for the application of Intuitionistic fuzzy soft set theory. Through a survey, the opportunities and selection of the students with the help of Intuitionistic fuzzy soft matrix operations along with Intuitionistic fuzzy max-min average composition method is discussed.

\section{Introduction}

Soft set theory was initiated by the Russian researcher Molodtsov [1]; he proposed soft set as a completely generic mathematical tool for modeling uncertainties. Maji et al. [2,3] applied this theory to several directions for dealing with the problems in uncertainty and imprecision. Pei and Miao [4] and Chen et al. [5] improved the work of Maji et al. [3]. Yang and Ji [6] initiated a matrix representation of a fuzzy soft set and applied it in decision making problems. Borah et al. [7] and Neog and Sut [8] extended fuzzy soft matrix theory and its application. Chetia and Das [9-11] proposed intuitionistic fuzzy soft matrix theory. Rajarajeswari and Dhanalakshmi [12-14] proposed new definitions for intuitionistic fuzzy soft matrices.

In real life most of the existing mathematical tools for formal modeling, reasoning, and computing are crisp, deterministic, and precise in nature. The classical crisp mathematical tools are not capable of dealing with the problems involving uncertainty and imprecision. There are many mathematical tools available for modeling complex systems such as probability theory, fuzzy set theory, and interval mathematics. Probability theory is applicable only for a stochastically stable system. Interval mathematics is not sufficiently adaptable for problems withdifferent uncertainties. Setting the membership function value is always a problem in fuzzy set theory. Intuitionistic fuzzy soft set theory (IFSS) may be more applicable to deal with uncertainty and imprecision; the parameterization tool using fuzzy soft set theory enhances the flexibility of its applications. Initially, intuitionistic fuzzy max-min average composition method is used.

In this paper, a new approach is proposed to construct the decision method for student selection using intuitionistic fuzzy soft matrices. In order to make this, addition, subtraction, and the complement of an intuitionistic fuzzy soft matrix (IFSM) are applied. The result is obtained based on the maximum value in the score matrix. An attempt has been made to provide a formal model of the process to study the selection of professional students by using IFSM theory and implement it in the form of field recommendation system. This is the system by which the recruiters use their knowledge to infer the selection from the skills displayed by the test results of the students and based on their selection criteria. A new technique called intuitionistic fuzzy revised max-min average composition method is proposed. Through a case study, it is seen that the proposed method produces 
better results than the existing max-min composition method $[15,16]$.

\section{Preliminaries}

The basic definitions of intuitionistic fuzzy soft set theory that are useful for subsequent discussions are given.

Definition 1 (see [1]). Suppose that $U$ is the universe of discourse and $E$ is a set of parameters; let $P(U)$ denote the power set of $U$. A pair $(F, E)$ is called a soft set over $U$, where $F$ is a mapping given by $F: E \rightarrow P(U)$. Clearly, a soft set is a mapping from parameters to $P(U)$, and it is not a set, but a parameterized family of subsets of the universe of discourse.

Definition 2 (see $[1,2]$ ). Let $U$ be the universe of discourse and let $E$ be the set of parameters. Let $A \subseteq E$. A pair $(F, A)$ is called fuzzy soft set over $U$, where $F$ is a mapping given by $F$ : $A \rightarrow I^{U}$ and $I^{U}$ denotes the collection of all fuzzy subsets of $U$.

Definition 3 (see $[1,2]$ ). Let $U$ be a universal set, $E$ a set of parameters, and $A \subset E$. Let $F(U)$ denote the set of all fuzzy subsets of $U$. A fuzzy soft set $\left(f_{A}, E\right)$ on the universe $U$ is defined as the set of ordered pairs $\left(f_{A}, E\right)=\left\{\left(e,\left(f_{A}(e)\right): e \in\right.\right.$ $\left.E, f_{A}(e) \in F(U)\right\}$, where $f_{A}: E \rightarrow F(U)$. Here, $f_{A}$ is called an approximate function of the fuzzy soft set $\left(f_{A}, E\right)$. The set $f_{A}(e)$ is called $e$ approximate value set or $e$-approximate set which consists of related objects of the parameter $e \in E$.

Definition 4 (see [3]). Let $U$ be an initial universe set and let $E$ be the set of parameters. Let $\mathrm{IF}^{U}$ denote the collection of all intuitionistic fuzzy subsets of $U$. Let $A \subset E$. A pair $(F ; A)$ is called an intuitionistic fuzzy soft set over $U$, where $F$ is a mapping given by $F: A \rightarrow \mathrm{IF}^{U}$.

Definition 5 (see [12]). Let $U=\left\{c_{1}, c_{2}, c_{3}, \ldots, c_{m}\right\}$ be the universal set and let $E=\left\{e_{1}, e_{2}, e_{3}, \ldots, e_{n}\right\}$ be the set of parameters. Let $A \subseteq E$ and let $(F, A)$ be a fuzzy soft set in the fuzzy soft class $(U, E)$. Then fuzzy soft set $(F, A)$ is a matrix form as $A_{m \times n}=\left[a_{i j}\right]_{m \times n}$ or $A=\left[a_{i j}\right], i=1,2, \ldots, m$ and $j=1,2,3, \ldots, n$, where

$$
a_{i j}= \begin{cases}\left(\mu_{j}\left(c_{i}\right), v_{j}\left(c_{i}\right)\right) & \text { if } e_{j} \in A \\ (0,1) & \text { if } e_{j} \notin A .\end{cases}
$$

$\mu_{j}\left(c_{i}\right)$ represents the membership of $c_{i}$ in the intuitionistic fuzzy set $F\left(e_{j}\right)$.

$v_{j}\left(c_{i}\right)$ represents the nonmembership of $c_{i}$ in the intuitionistic fuzzy set $F\left(e_{j}\right)$.

Example 6 (see [14]). Suppose that $U=\left\{P_{1}, P_{2}, P_{3}, P_{4}\right\}$ is a set of students and $E=\left\{S_{1}, S_{2}, S_{3}, S_{4}\right\}$ is a set of parameters, which stand for results, technical skills, analytical skills, presentation skills, and communication skills, respectively. Consider the mapping from parameters set to the set of all intuitionistic fuzzy subsets of power set $U$. Then intuitionistic fuzzy soft set $(F, A)$ describes the skills of the students with respect to the given parameters, for finding the best student of an academic year. Consider $A=\left\{S_{1}, S_{2}, S_{3}, S_{4}\right\}$; then intuitionistic fuzzy soft set is

$$
\begin{array}{r}
(F, A)=\left\{F\left(S_{1}\right)=\left\{\left(P_{1}, 0.8,0.1\right),\left(P_{2}, 0.3,0.6\right),\right.\right. \\
\left.\left(P_{3}, 0.4,0.5\right),\left(P_{4}, 0.6,0.1\right)\right\} \\
F\left(S_{2}\right)=\left\{\left(P_{1}, 0.6,0.1\right),\left(P_{2}, 0.4,0.4\right),\right. \\
\left.\quad\left(P_{3}, 0.5,0.4\right),\left(P_{4}, 0.8,0.1\right)\right\} \\
F\left(S_{3}\right)=\left\{\left(P_{1}, 0.4,0.6\right),\left(P_{2}, 0.4,0.5\right),\right. \\
\left.\quad\left(P_{3}, 0.8,0.2\right),\left(P_{4}, 0.3,0.4\right)\right\} \\
F\left(S_{4}\right)=\left\{\left(P_{1}, 0.6,0.1\right),\left(P_{2}, 0.7,0.2\right),\right. \\
\left.\left.\quad\left(P_{3}, 0.6,0.3\right),\left(P_{4}, 0.7,0.2\right)\right\}\right\} .
\end{array}
$$

This intuitionistic fuzzy soft set is represented by the following intuitionistic fuzzy soft matrix:

A

$\begin{gathered}S_{1} \\ P_{1} \\ P_{2} \\ P_{3} \\ P_{4}\end{gathered}\left[\begin{array}{cccc}(0.8,0.1) & (0.6,0.1) & (0.4,0.6) & (0.6,0.1) \\ (0.3,0.6) & (0.4,0.4) & (0.4,0.5) & (0.7,0.2) \\ (0.4,0.5) & (0.5,0.4) & (0.8,0.2) & (0.6,0.3) \\ (0.6,0.1) & (0.8,0.1) & (0.3,0.4) & (0.7,0.2)\end{array}\right]$.

Definition 7 (see [12]). If $A=\left[a_{i j}\right] \in \operatorname{IFSM}_{m \times n}$ and $B=$ $\left[b_{i j}\right] \in \operatorname{IFSM}_{m \times n}$, then we define the addition and subtraction of intuitionistic fuzzy soft matrices of $A$ and $B$ as

$$
\begin{aligned}
A+B=\{ & \max \left[\mu_{A}\left(a_{i j}\right), \mu_{B}\left(b_{i j}\right)\right], \\
& \left.\min \left[v_{A}\left(a_{i j}\right), v_{B}\left(b_{i j}\right)\right]\right\}, \quad \forall i, j \\
A-B=\left\{\min \left[\mu_{A}\left(a_{i j}\right), \mu_{B}\left(b_{i j}\right)\right],\right. & \\
& \left.\max \left[v_{A}\left(a_{i j}\right), v_{B}\left(b_{i j}\right)\right]\right\}, \quad \forall i, j .
\end{aligned}
$$

Definition 8 (see [12]). Let $A=\left[a_{i j}\right] \in \operatorname{IFSM}_{m \times n}$, where $a_{i j}=$ $\left(\mu_{j}\left(c_{i}\right), v_{j}\left(c_{i}\right)\right)$ for all $i, j$. Then $A^{C}$ is called an intuitionistic fuzzy soft complement matrix if $A^{C}=\left[d_{i j}\right]_{m \times n}$, where $d_{i j}=$ $\left(\nu_{j}\left(c_{i}\right), \mu_{j}\left(c_{i}\right)\right)$ for all $i, j$.

Definition 9 (see [13]). If $A=\left[a_{i j}\right] \in \operatorname{IFSM}_{m \times n}, B=$ $\left[b_{j k}\right] \in \operatorname{IFSM}_{n \times p}$, then max min composition fuzzy soft matrix relation of $A$ and $B$ is defined as

$$
A * B=\left[c_{i k}\right]_{m \times p},
$$

where

$$
\begin{gathered}
c_{i k}=\left\{\operatorname{Max}\left\{\operatorname{Min}_{j}\left[\mu_{A}\left(a_{i j}\right), \mu_{B}\left(b_{j k}\right)\right]\right\},\right. \\
\left.\operatorname{Min}\left\{\operatorname{Max}_{j}\left[\nu_{A}\left(a_{i j}\right), \nu_{B}\left(b_{j k}\right)\right]\right\}\right\} .
\end{gathered}
$$


Definition 10. If $A=\left[a_{i j}\right] \in \operatorname{IFSM}_{m \times n}$ and $B=\left[b_{j k}\right] \epsilon$ IFSM $_{n \times p}$, then a new operation called revised intuitionistic fuzzy max-min average composition for fuzzy soft matrix relation is defined as

$$
\begin{aligned}
A \Phi B=\left\{\operatorname{Max}\left\{\frac{\mu_{A}\left(a_{i j}\right)+\mu_{B}\left(b_{j k}\right)}{2}\right\},\right. & \\
& \left.\operatorname{Min}\left\{\frac{v_{A}\left(a_{i j}\right)+v_{B}\left(b_{j k}\right)}{2}\right\}\right\}, \quad \forall i, j .
\end{aligned}
$$

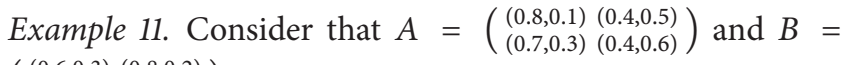
$\left(\begin{array}{ll}(0.6,0.3) & (0.8,0.2) \\ (0.7,0.3) & (0.5,0.5)\end{array}\right)$ are the two intuitionistic fuzzy soft matrices; then the addition, subtraction, complement, max-min composition, and max-min average composition of fuzzy soft matrix relations are

$$
\begin{gathered}
A+B=\left(\begin{array}{ll}
(0.8,0.1) & (0.8,0.2) \\
(0.7,0.3) & (0.5,0.5)
\end{array}\right) \\
A-B=\left(\begin{array}{ll}
(0.6,0.3) & (0.4,0.5) \\
(0.7,0.3) & (0.4,0.6)
\end{array}\right) \\
A^{C}=\left(\begin{array}{ll}
(0.1,0.8) & (0.5,0.4) \\
(0.3,0.7) & (0.6,0.4)
\end{array}\right) \\
A * B=\left(\begin{array}{ll}
(0.6,0.3) & (0.8,0.2) \\
(0.6,0.3) & (0.7,0.3)
\end{array}\right) \\
A \Phi B=\left(\begin{array}{cc}
(0.70,0.20) & (0.80,0.15) \\
(0.65,0.3) & (0.75,0.25)
\end{array}\right) .
\end{gathered}
$$

Definition 12. If $A=\left[a_{i j}\right] \in \operatorname{IFSM}_{m \times n}, B=\left[b_{i j}\right] \in \operatorname{IFSM}_{m \times n}$, and $A^{C}, B^{C}$ are the complement of $A$ and $B$ then the score matrix of $A$ and $B$ is defined as $S(A, B)=(1 / 2)[V+W]$, where $V$ is the matrix defined as $V=\left[\left(\mu_{A \Phi B}-v_{A^{C} \phi B^{C}}\right)\right]$ and $W$ is the matrix defined as $W=\left[\left(\mu_{A^{C} \Phi B^{C}}-\nu_{A \phi B}\right)\right]$.

\section{Intuitionistic Fuzzy Max-Min Average Composition Method for Decision Making}

In this section an application of intuitionistic fuzzy soft set theory using max-min average composition method for decision making is presented.

In a given set of systems, let $P=\left\{P_{1}, P_{2}, \ldots, P_{m}\right\}$ be the set of $m$ students and let $S=\left\{S_{1}, S_{2}, \ldots, S_{n}\right\}$ be the set of $n$ skills and let $D=\left\{D_{1}, D_{2}, \ldots, D_{k}\right\}$ be the set of $k$ opportunities.

Now construct an intuitionistic fuzzy soft set $(F, S)$ over $P$, where $F$ is a mapping $F: S \rightarrow \operatorname{IF}^{P}$ and $\operatorname{IF}^{P}$ is the collection of all intuitionistic fuzzy subsets of $P$. This intuitionistic fuzzy soft set gives a matrix $A$ called student-skills matrix (as in Example 6).

Then construct another intuitionistic fuzzy soft set $(G, D)$ over $S$, where $G$ is a mapping $G: D \rightarrow \mathrm{IF}^{S}$ and $\mathrm{IF}^{S}$ is the collection of all intuitionistic fuzzy subsets of $S$. This intuitionistic fuzzy soft set gives a matrix $B$ called skillsopportunities matrix, where each element denotes the weight of the skills for certain opportunities.
Using Definition 8, obtain the intuitionistic fuzzy soft complement matrices $A^{c}, B^{c}$.

Using Definitions 10 and 12, compute $A \Phi B, A^{c} \Phi B^{c}$, and the score matrix $S(A, B)$.

Finally find the maximum value for each student $P_{i}$ in the score matrix and then conclude that the student $P_{i}$ is suitable for the opportunity $D_{j}$.

\subsection{Algorithm}

Step 1. Input the intuitionistic fuzzy soft sets $(F, S),(G, D)$ and obtain the intuitionistic fuzzy soft matrices $A, B$ corresponding to $(F, S)$ and $(G, D)$, respectively.

Step 2. Using Definition 8, obtain the intuitionistic fuzzy soft complement matrices $A^{c}, B^{c}$.

Step 3. Using Definition 10, compute the intuitionistic fuzzy max-min average compositions $A \Phi B$ and $A^{c} \Phi B^{c}$.

Step 4. Compute the matrices $V, W$ and obtain the score matrix $S(A, B)$ using Definition 12.

Step 5. Identify the maximum score in $S(A, B)$ for each student $P_{i}$ to select the suitable opportunity.

\section{Case Study}

Consider $P=\left\{P_{1}, P_{2}, P_{3}, P_{4}\right\}$ as the universal set, where $P_{1}, P_{2}, P_{3}$, and $P_{4}$ represent the set of students Arun, John, Peter, and Ram. Again consider $S=\left\{S_{1}, S_{2}, S_{3}, S_{4}\right\}$ as the set of skills, where $S_{1}, S_{2}, S_{3}, S_{4}$ represent technical skills, analytical skills, presentation skills, and communication skills, respectively, for the case study. Let the possible opportunities relating to the above skills be $D=\left\{D_{1}, D_{2}, D_{3}\right\}$, where $D_{1}, D_{2}, D_{3}$ represent hardware, software, and others.

Suppose that IFSS $(F, S)$ over $P$, where $F$ is a mapping $F: S \rightarrow \mathrm{IF}^{P}$, gives the description of student-skills relation based on the test result by using intuitionistic fuzzy matrix relation in the form of IFS:

$$
\begin{array}{r}
(F, S)=\left\{F\left(S_{1}\right)=\left\{\left(P_{1}, 0.8,0.1\right),\left(P_{2}, 0.3,0.6\right),\right.\right. \\
\left.\left(P_{3}, 0.4,0.5\right),\left(P_{4}, 0.6,0.1\right)\right\} \\
F\left(S_{2}\right)=\left\{\left(P_{1}, 0.6,0.1\right),\left(P_{2}, 0.4,0.4\right),\right. \\
\left.\quad\left(P_{3}, 0.5,0.4\right),\left(P_{4}, 0.8,0.1\right)\right\} \\
F\left(S_{3}\right)=\left\{\left(P_{1}, 0.4,0.6\right),\left(P_{2}, 0.4,0.5\right),\right. \\
\left.\quad\left(P_{3}, 0.8,0.2\right),\left(P_{4}, 0.3,0.4\right)\right\} \\
F\left(S_{4}\right)=\left\{\left(P_{1}, 0.6,0.1\right),\left(P_{2}, 0.7,0.2\right),\right. \\
\left.\left.\quad\left(P_{3}, 0.6,0.3\right),\left(P_{4}, 0.7,0.2\right)\right\}\right\} .
\end{array}
$$


This intuitionistic fuzzy soft set is represented by the following intuitionistic fuzzy soft matrix:

A

$$
\begin{gathered}
S_{1} \\
P_{1} \\
P_{2} \\
P_{3} \\
P_{4}
\end{gathered}\left[\begin{array}{cccc}
(0.8,0.1) & (0.6,0.1) & (0.4,0.6) & (0.6,0.1) \\
(0.3,0.6) & (0.4,0.4) & (0.4,0.5) & (0.7,0.2) \\
(0.4,0.5) & (0.5,0.4) & (0.8,0.2) & (0.6,0.3) \\
(0.6,0.1) & (0.8,0.1) & (0.3,0.4) & (0.7,0.2)
\end{array}\right] .
$$

Suppose that IFSS $(G, D)$ over $S$, where $G$ is a mapping $G: D \rightarrow \mathrm{IF}^{S}$, gives the weight of the skills for certain opportunities by field expert using intuitionistic fuzzy matrix relation in the form of IFS:

$$
\begin{aligned}
& \text { Let }(G, D)=\left\{G\left(D_{1}\right)=\left\{\left(S_{1}, 0.7,0.2\right),\left(S_{2}, 0.8,0.1\right),\right.\right. \\
& \\
& \qquad \begin{aligned}
&\left.\left(S_{3}, 0.4,0.3\right),\left(S_{4}, 0.5,0.3\right)\right\} \\
& G\left(D_{2}\right)=\left\{\left(S_{1}, 0.5,0.4\right),\left(S_{2}, 0.4,0.5\right),\right. \\
&\left.\left(S_{3}, 0.8,0.1\right),\left(S_{4}, 0.6,0.2\right)\right\} \\
& G\left(D_{3}\right)=\left\{\left(S_{1}, 0.4,0.5\right),\left(S_{2}, 0.6,0.3\right),\right. \\
&\left.\left.\left(S_{3}, 0.4,0.4\right),\left(S_{4}, 0.7,0.1\right)\right\}\right\} .
\end{aligned}
\end{aligned}
$$

This intuitionistic fuzzy soft set is represented by the following intuitionistic fuzzy soft matrix:

$$
B=S_{2} \quad\left[\begin{array}{ccc}
D_{1} & D_{2} & D_{3} \\
& S_{3} \\
S_{3} & S_{4}
\end{array}\left[\begin{array}{ccc}
(0.7,0.2) & (0.5,0.4) & (0.4,0.5) \\
(0.4,0.3) & (0.4,0.5) & (0.6,0.3) \\
(0.5,0.3) & (0.6,0.1) & (0.4,0.4) \\
& & (0.7,0.1)
\end{array}\right]\right.
$$

Then calculate the intuitionistic fuzzy soft complement matrices using Definition 8 as follows:

$$
\begin{gathered}
A^{C} \\
\begin{array}{c}
S_{1} \\
P_{1} \\
P_{2} \\
P_{3} \\
P_{4}
\end{array}\left[\begin{array}{cccc}
(0.1,0.8) & (0.1,0.6) & (0.6,0.4) & (0.1,0.6) \\
(0.6,0.3) & (0.4,0.4) & (0.5,0.4) & (0.2,0.7) \\
(0.5,0.4) & (0.4,0.5) & (0.2,0.8) & (0.3,0.6) \\
(0.1,0.6) & (0.1,0.8) & (0.4,0.3) & (0.2,0.7)
\end{array}\right] . \\
B^{C}= \\
S_{1} \quad\left[\begin{array}{ccc}
(0.2,0.7) & (0.4,0.5) & (0.5,0.4) \\
(0.1,0.8) & (0.5,0.4) & (0.3,0.6) \\
(0.3,0.4) & (0.1,0.8) & (0.4,0.4) \\
(0.3,0.5) & (0.2,0.6) & (0.1,0.7)
\end{array}\right] .
\end{gathered}
$$

Then the intuitionistic fuzzy max-min average composition relation matrices are obtained using Definition 10 :

$A \Phi B$

$$
\begin{gathered}
D_{1} \\
p_{1} \\
p_{2} \\
p_{3} \\
p_{4}
\end{gathered}\left[\begin{array}{ccc}
(0.75,0.10) & D_{2} & D_{3} \\
(0.60,0.25) & (0.65,0.15) & (0.60,0.10) \\
(0.60,0.25) & (0.80,0.20) & (0.70,0.15) \\
(0.80,0.10) & (0.65,0.20) & (0.70,0.15)
\end{array}\right]
$$

$A^{c} \Phi B^{c}$

$$
\begin{gathered}
D_{1} \\
p_{1} \\
p_{2} \\
p_{3} \\
p_{4}
\end{gathered} \quad\left[\begin{array}{ccc}
(0.45,0.40) & D_{2} & D_{3} \\
(0.40,0.40) & (0.40,0.50) & (0.50,0.40) \\
(0.35,0.55) & (0.45,0.45) & (0.50,0.35) \\
(0.35,0.35) & (0.30,0.55) & (0.40,0.40) \\
\end{array}\right] .
$$

Find the matrices $V$ and $W$ using Definition 12 as follows:

$$
\begin{aligned}
& V=\left[\left(\mu_{A \Phi B}-v_{A^{C} \phi B^{C}}\right)\right]=\begin{array}{c}
D_{1} \\
P_{1} \\
P_{2} \\
P_{3} \\
P_{4}
\end{array}\left[\begin{array}{ccc}
0.35 & 0.15 & 0.20 \\
0.20 & 0.25 & 0.35 \\
0.05 & 0.35 & 0.25 \\
0.45 & 0.10 & 0.35
\end{array}\right],
\end{aligned}
$$

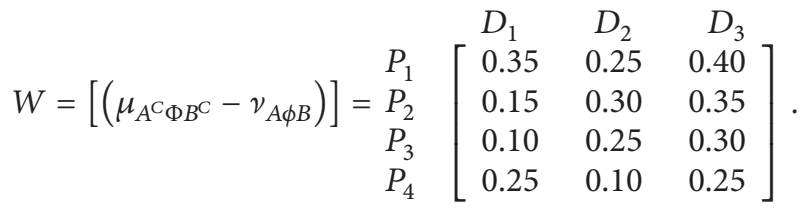

Using Definition 12, the score matrix for intuitionistic fuzzy max-min average composition method is

$$
S(A, B)=\frac{1}{2}[V+W]=\begin{gathered}
D_{1} \\
P_{1} \\
P_{2} \\
P_{3} \\
P_{4}
\end{gathered}\left[\begin{array}{ccc}
\mathbf{0 . 3 5} & 0.20 & 0.30 \\
0.18 & 0.28 & \mathbf{0 . 3 5} \\
0.08 & \mathbf{0 . 3 0} & 0.28 \\
\mathbf{0 . 3 5} & 0.10 & 0.30
\end{array}\right] .
$$

It is clear from the above result that the interviewer agrees that the max values of Arun $\left(P_{1}\right)$ and $\operatorname{Ram}\left(P_{4}\right)$ are 0.35; they are suitable for hardware profession whereas the max value of Peter $\left(P_{3}\right)$ is 0.30 who is suitable for software profession. John $\left(P_{2}\right)$ is suitable for the profession other than hardware and software. This is represented by the chart diagram as shown in Figure 1.

Using Definition 9 and the method discussed in [13], the same problem is solved and the respective score matrix denoted by $S_{\max -\min }$ is obtained as follows:

$$
S_{\text {max-min }}=\begin{array}{ccc}
D_{1} & D_{2} & D_{3} \\
P_{1} & P_{2} \\
P_{3} \\
P_{4}
\end{array}\left[\begin{array}{ccc}
\mathbf{0 . 6 0} & 0.40 & 0.50 \\
0.30 & \mathbf{0 . 4 0} & \mathbf{0 . 4 0} \\
0.30 & \mathbf{0 . 6 0} & 0.30 \\
\mathbf{0 . 7 0} & 0.40 & 0.50
\end{array}\right]
$$




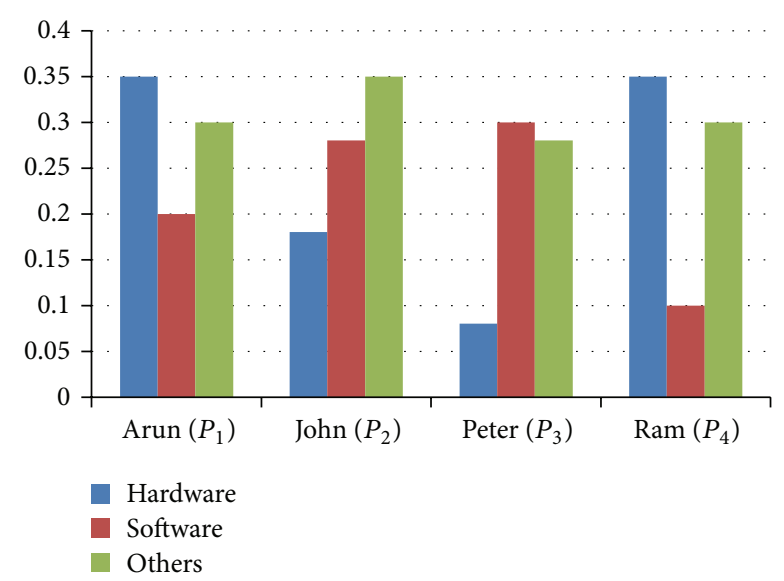

FIgURe 1

\section{Conclusions}

Compared with conventional techniques, the proposed approach in decision making effectively reduces the conflict in making decisions. For example, the maximum score in the second row of the score matrix $S_{\text {max-min }}$ is 0.40 which corresponds to more than one opportunity and there arises a conflict in making decision whereas it is not the case in the proposed method. Also, our approach makes it possible to introduce weights for all skills and reduces the confusion about the possibility of two opportunities in a student and also the proposed method is an effective tool for the decision making problems. In the future many decision making problems involving three or more sets of relation can be effectively modeled using our approach.

\section{Conflict of Interests}

The authors declare that there is no conflict of interests regarding the publication of this paper.

\section{References}

[1] D. Molodtsov, "Soft set theory-first results," Computers and mathematics with Applications, vol. 37, no. 4-5, pp. 19-31, 1999.

[2] P. K. Maji, R. Biswas, and A. R. Roy, "Fuzzy soft sets," Journal of Fuzzy Mathematics, vol. 9, no. 3, pp. 589-602, 2001.

[3] P. K. Maji, A. R. Roy, and R. Biswas, "On intuitionistic fuzzy soft sets," Journal of Fuzzy Mathematics, vol. 12, no. 3, pp. 669-683, 2004.

[4] D. Pei and D. Miao, "From soft sets to information systems," in Proceedings of the IEEE International Conference on Granular Computing, vol. 2, pp. 617-621, July 2005.

[5] D. Chen, E. C. C. Tsang, D. S. Yeung, and X. Wang, "The parameterization reduction of soft sets and its applications," Computers and Mathematics with Applications, vol. 49, no. 5-6, pp. 757-763, 2005.

[6] Y. Yang and C. Ji, "Fuzzy soft matrices and their applications," in Artificial Intelligence and Computational Intelligence, vol. 7002 of Lecture Notes in Computer Science, pp. 618-627, 2011.
[7] M. J. Borah, T. J. Neog, and D. K. Sut, "Fuzzy soft matrix theory and its decision making," International Journal of Modern Engineering Research, vol. 2, pp. 121-127, 2012.

[8] T. J. Neog and D. K. Sut, "An application of fuzzy soft sets in decision making problems using fuzzy soft matrices," International Journal of Mathematical Archive, vol. 2, pp. 2258-2263, 2012.

[9] B. Chetia and P. K. Das, "On Fuzzy Soft Matrix Theory," Journal of the Assam Academy of Mathematics, vol. 2, pp. 71-83, 2010.

[10] B. Chetia and P. K. Das, “On Fuzzy Soft Sets," International Journal of Mathematical Archive, vol. 2, pp. 1-6, 2011.

[11] B. Chetia and P. K. Das, "Some results of intuitionistic fuzzy soft matrix theory," Pelagia Research Library, Advances in Applied Science Research, vol. 3, no. 1, pp. 412-423, 2012.

[12] P. Rajarajeswari and P. Dhanalakshmi, "Intuitionistic fuzzy soft matrix theory and its application in decision making," International Journal of Engineering Research and Technology, vol. 2, no. 4, pp. 1100-1111, 2013.

[13] P. Rajarajeswari and P. Dhanalakshmi, "Intuitionistic fuzzy soft matrix theory and its application in medical diagnosis," Annals of Fuzzy Mathematics and Informatics, vol. 2, pp. 1-11, 2013.

[14] P. Rajarajeswari and P. Dhanalakshmi, "Similarity measures of intuitionistic fuzzy soft sets and their application in medical diagnosis," International Journal of Mathematical Archive, vol. 5, no. 5, pp. 143-149, 2014.

[15] P. Shanmugasundaram and C. V. Seshaiah, "An application of intuitionistic fuzzy technique in medical diagnosis," Australian Journal of Basic and Applied Sciences, vol. 8, no. 9, pp. 392-395, 2014.

[16] P. Shanmugasundaram, C. V. Seshaiah, and K. Rathi, "Intuitionistic fuzzy soft matrix theory in medical diagnosis using maxmin average composition method," Accepted for publication in Journal of Theoretical and Applied Information Technology, 2014. 

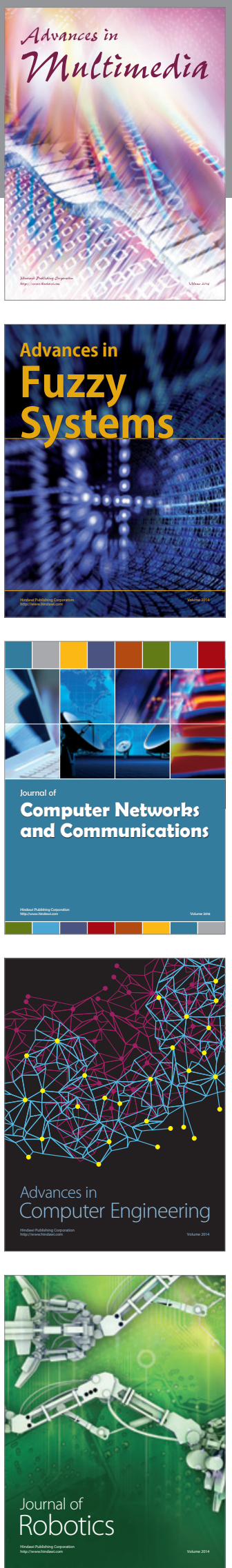

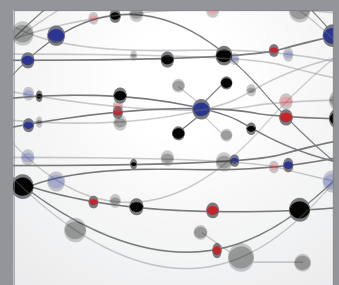

The Scientific World Journal
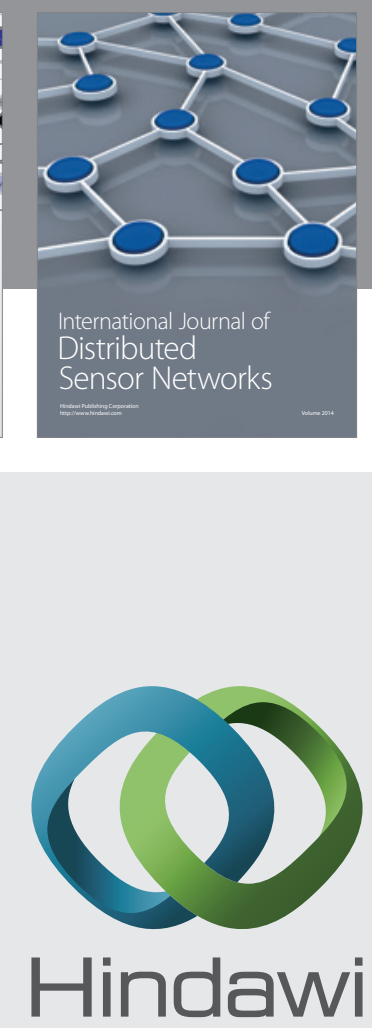

Submit your manuscripts at

http://www.hindawi.com
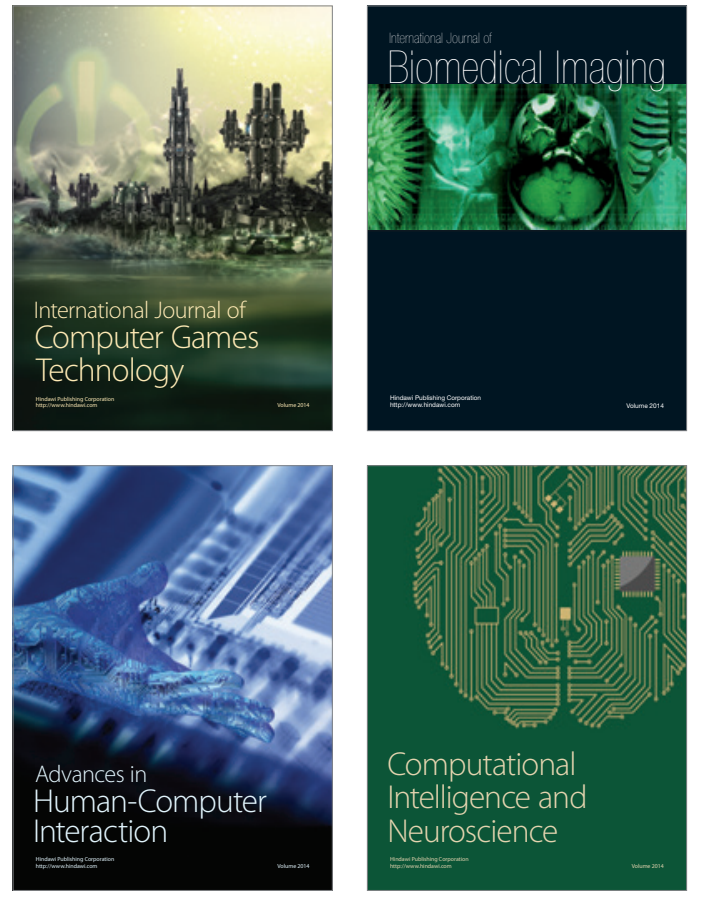
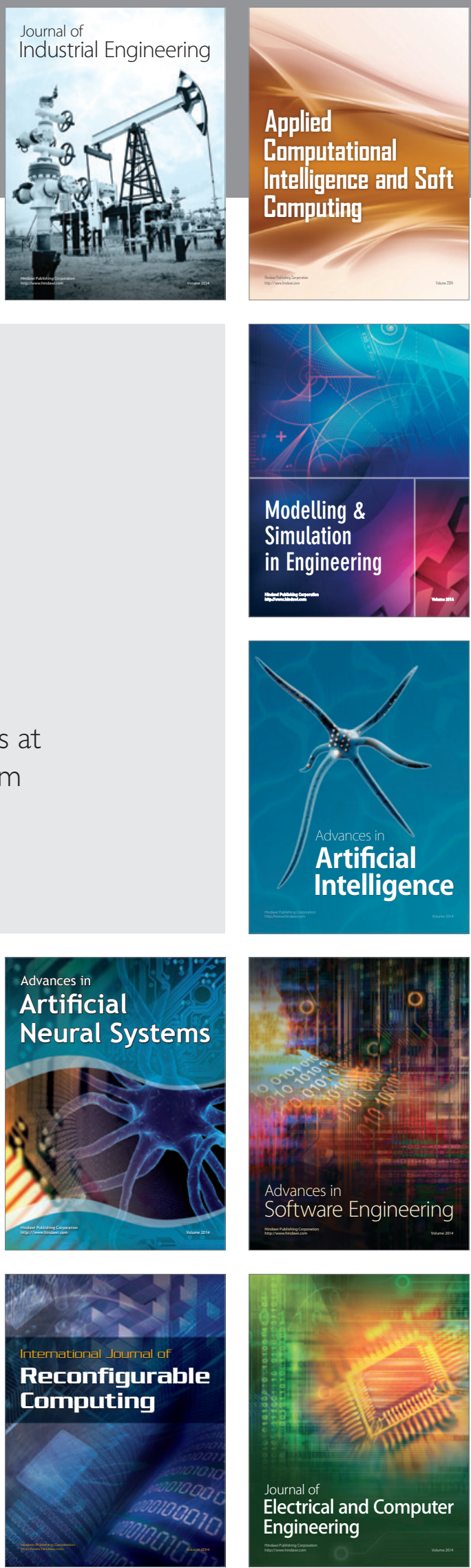